\title{
Corrigendum: HAX-1 Protects Glioblastoma Cells From Apoptosis Through the Akt1 Pathway
}

\begin{abstract}
Xin Deng ${ }^{1}$, Laijun Song ${ }^{1}$, Wen Zhao ${ }^{2,3,4}$, Ying Wei ${ }^{5}$ and Xin-bin Guo ${ }^{5 *}$
${ }^{1}$ Department of Neurosurgery, The First Affiliated Hospital of Zhengzhou University, Zhengzhou, China, ${ }^{2}$ Key Laboratory of Advanced Pharmaceutical Technology, Ministry of Education of China, Zhengzhou, China, ${ }^{3}$ Co-innovation Center of Henan Province for New Drug R \& D and Preclinical Safety, Zhengzhou, China, ${ }^{4}$ School of Pharmaceutical Sciences, Zhengzhou University, Zhengzhou, China, ${ }^{5}$ Department of Neuro-interventional Radiology, The First Affiliated Hospital of Zhengzhou University, Zhengzhou, China
\end{abstract}

Keywords: glioblastoma, HAX-1, Akt1, Hsp90, apoptosis

\section{OPEN ACCESS}

Edited and reviewed by: José A. G. Agúndez, University of Extremadura, Spain

*Correspondence: Xin-bin Guo gxb3906080@126.com; gxb3906080@sina.com

Received: 27 December 2018 Accepted: 14 January 2019 Published: 31 January 2019

Citation: Deng $X$, Song L, Zhao W, Wei Y and Guo X (2019) Corrigendum: HAX-1

Protects Glioblastoma Cells From Apoptosis Through the Akt1 Pathway.

Front. Cell. Neurosci. 13:13.

doi: 10.3389/fncel.2019.00013

\section{A Corrigendum on}

HAX-1 Protects Glioblastoma Cells from Apoptosis through the Akt1 Pathway by Deng, X., Song, L., Zhao, W., Wei, Y., and Guo, X. (2017). Front. Cell. Neurosci. 11:420. doi: 10.3389/fncel.2017.00420

In the original article, there was a mistake in Figure 1B U118 KO-1 and KO-2 as published. In Figure 1, the images for B U118 KO-1 and KO-2 were incorrectly provided. The corrected Figure 1B U118 KO-1 and KO-2 appears below.

The authors apologize for this error and state that this does not change the scientific conclusions of the article in any way. The original article has been updated.

Conflict of Interest Statement: The authors declare that the research was conducted in the absence of any commercial or financial relationships that could be construed as a potential conflict of interest.

Copyright (c) 2019 Deng, Song, Zhao, Wei and Guo. This is an open-access article distributed under the terms of the Creative Commons Attribution License (CC BY). The use, distribution or reproduction in other forums is permitted, provided the original author(s) and the copyright owner(s) are credited and that the original publication in this journal is cited, in accordance with accepted academic practice. No use, distribution or reproduction is permitted which does not comply with these terms. 
A

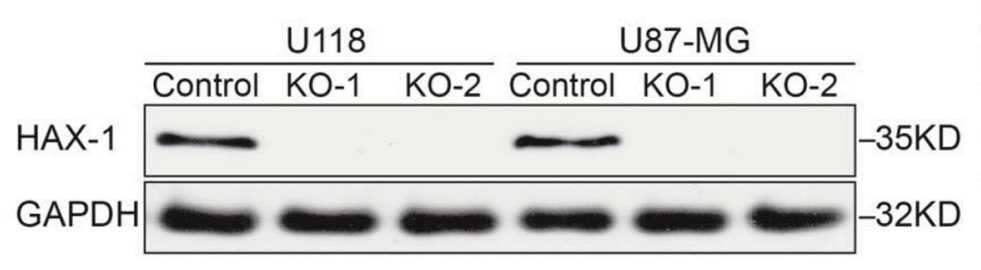

B

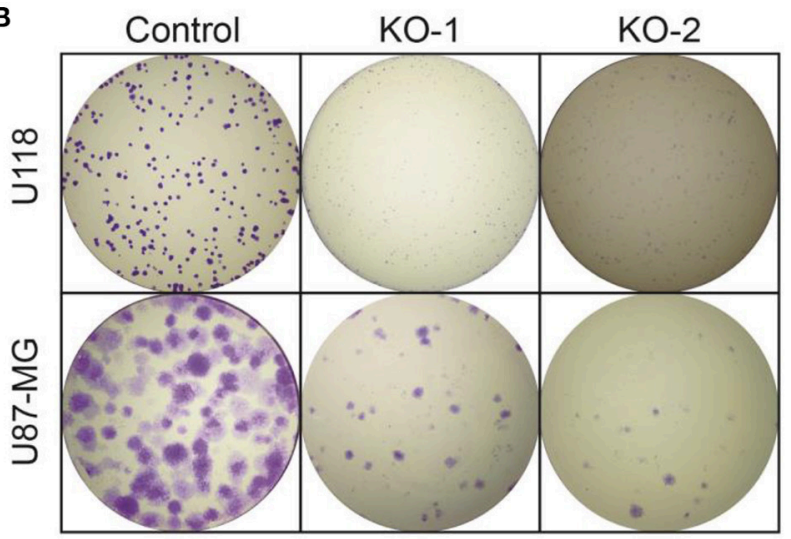

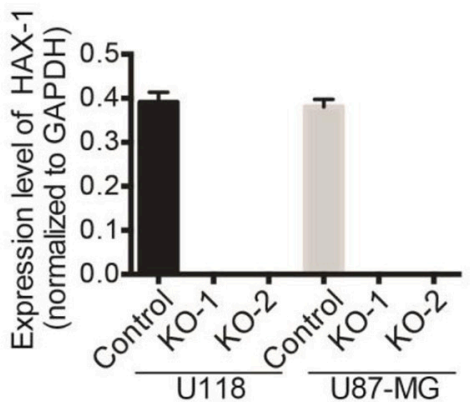
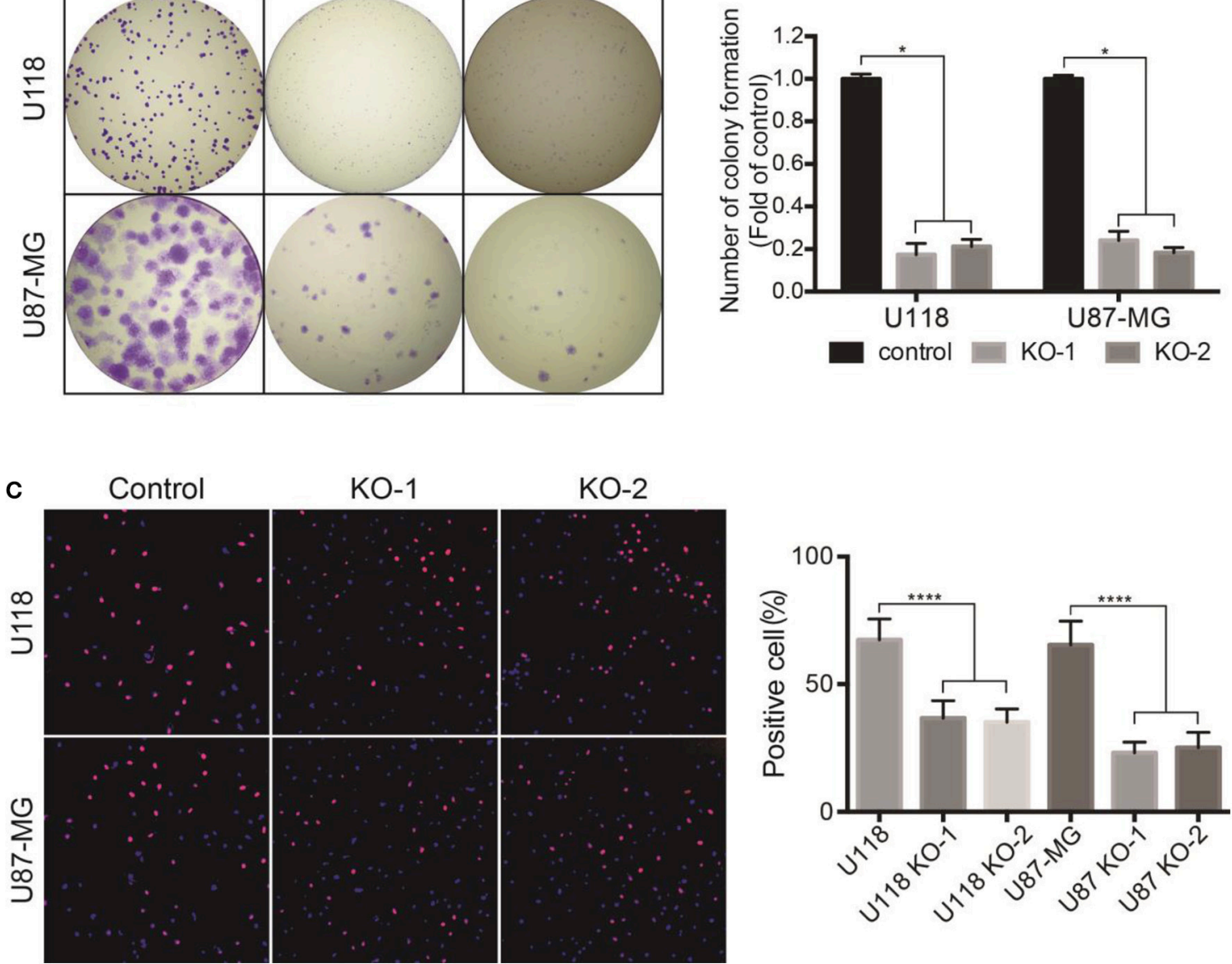

FIGURE 1 | HAX-1 regulated cell proliferation of glioblastoma cells. (A) Western blot showed that HAX-1 was completely knocked out in U118 and U87-MG. GAPDH was used as a loading control. (B) Colony formation assays indicated that the efficiency of colony formation of U118 and U87-MG cells declined after HAX-1 was knocked out. (C) Edu proliferation assays showed decreased proliferative U118 and U87-MG cells. Edu was labeled with red fluorescence and nuclei were stained with blue fluorescence. (magnification: $100 \times$ ) Three individual experiments were performed for each group. ${ }^{*} P<0.05,{ }^{* * * *} P<0.0001$. 